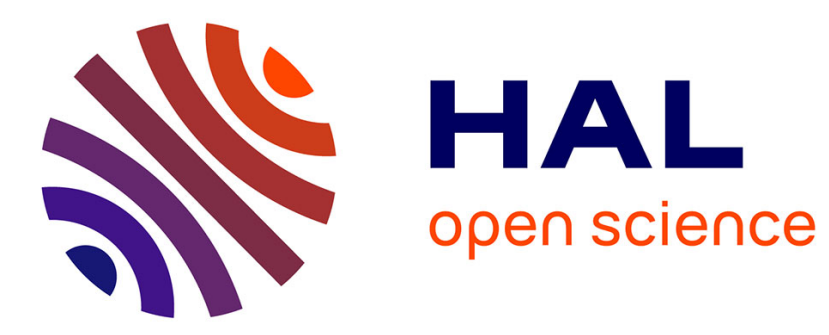

\title{
Effect of various upper limb multibody models on soft tissue artefact correction: A case study
}

Alexandre Naaim, Florent Moissenet, Sonia Duprey, Mickaël Begon, Laurence Cheze

\section{- To cite this version:}

Alexandre Naaim, Florent Moissenet, Sonia Duprey, Mickaël Begon, Laurence Cheze. Effect of various upper limb multibody models on soft tissue artefact correction: A case study. Journal of Biomechanics, 2017, 62, pp.102-109. 10.1016/j.jbiomech.2017.01.031 . hal-01635819

\section{HAL Id: hal-01635819 https://hal.science/hal-01635819}

Submitted on 15 Nov 2017

HAL is a multi-disciplinary open access archive for the deposit and dissemination of scientific research documents, whether they are published or not. The documents may come from teaching and research institutions in France or abroad, or from public or private research centers.
L'archive ouverte pluridisciplinaire HAL, est destinée au dépôt et à la diffusion de documents scientifiques de niveau recherche, publiés ou non, émanant des établissements d'enseignement et de recherche français ou étrangers, des laboratoires publics ou privés. 


\section{Accepted Manuscript}

Effect of various upper limb multibody models on soft tissue artefact correction:

A case study

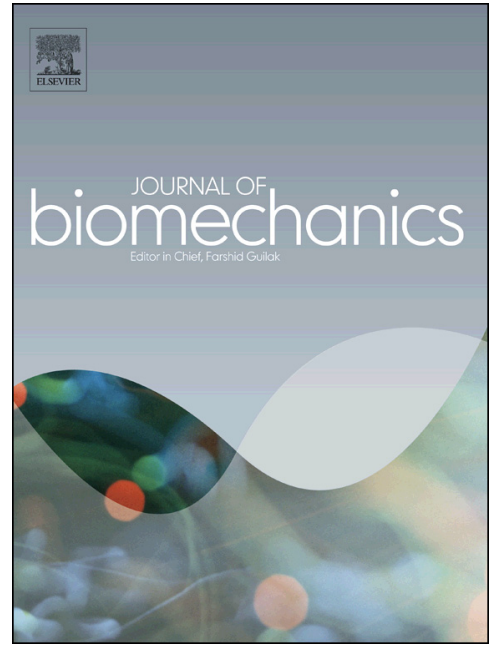

Alexandre Naaim, Florent Moissenet, Sonia Duprey, Mickaël Begon, Laurence

Chèze

PII:

S0021-9290(17)30044-1

DOI:

http://dx.doi.org/10.1016/j.jbiomech.2017.01.031

Reference:

BM 8103

To appear in:

Journal of Biomechanics

Accepted Date:

16 January 2017

Please cite this article as: A. Naaim, F. Moissenet, S. Duprey, M. Begon, L. Chèze, Effect of various upper limb multibody models on soft tissue artefact correction: A case study, Journal of Biomechanics (2017), doi: http:// dx.doi.org/10.1016/j.jbiomech.2017.01.031

This is a PDF file of an unedited manuscript that has been accepted for publication. As a service to our customers we are providing this early version of the manuscript. The manuscript will undergo copyediting, typesetting, and review of the resulting proof before it is published in its final form. Please note that during the production process errors may be discovered which could affect the content, and all legal disclaimers that apply to the journal pertain. 
Effect of various upper limb multibody models on soft tissue artefact correction: a case study

Alexandre Naaim ${ }^{1-2^{*}}$, Florent Moissenet ${ }^{3}$, Sonia Duprey ${ }^{2,4}$, Mickaël Begon ${ }^{4,5}$, Laurence Chèze ${ }^{2}$

${ }^{1}$ CIC INSERM 1432, Plateforme d'Investigation Technologique, CHU Dijon, France

${ }^{2}$ Univ Lyon, Université Claude Bernard Lyon 1, IFSTTAR, LBMC UMR_T9406, F69622, Lyon, France

${ }^{3}$ CNRFR - Rehazenter, Laboratoire d'Analyse du Mouvement et de la Posture, 1 rue André Vésale, L-2674 Luxembourg, Luxembourg

${ }^{4}$ Laboratoire de simulation et de modélisation du mouvement, Département de kinésiologie, Université de Montréal, 1700, rue Jacques Tétreault, Laval, QC H7N 0B6, Canada

${ }^{5}$ Research Center, Sainte-Justine Hospital, 3175 Côte-Ste-Catherine, Montreal, Quebec, Canada H3T 1C5

*Corresponding author:

Alexandre NAAIM

CIC INSERM 1432,

Plateforme d'Investigation Technologique, CHU Dijon,

23a rue Paul Gafarel

BP 77908 -21076 Dijon CEDEX

France

Email: alexandre.naaim@chu-dijon.fr

\section{Original article - Word Count: 3498 words}




\begin{abstract}
Soft tissue artefacts (STA) introduce errors in joint kinematics when using cutaneous markers, especially on the scapula. Both segmental optimisation and multibody kinematics optimisation (MKO) algorithms have been developed to improve kinematics estimates. MKO based on a chain model with joint constraints avoids apparent joint dislocation but is sensitive to the biofidelity of chosen joint constraints. Since no recommendation exists for the scapula, our objective was to determine the best models to accurately estimate its kinematics. One participant was equipped with skin markers and with an intracortical pin screwed in the scapula. Segmental optimisation and MKO for 24-chain models (including four variations of the scapulothoracic joint) were compared against the pin-derived kinematics using root mean square error (RMSE) on Cardan angles. Segmental optimisation led to an accurate scapula kinematics $\left(1.1^{\circ} \leq \mathrm{RMSE} \leq 3.3^{\circ}\right)$ even for high arm elevation angles. When MKO was applied, no clinically significant difference was found between the different scapulothoracic models $\left(0.9^{\circ} \leq \mathrm{RMSE} \leq 4.1^{\circ}\right)$ except when a free scapulothoracic joint was modelled $\left(1.9^{\circ} \leq \mathrm{RMSE} \leq 9.6^{\circ}\right)$. To conclude, using MKO as a STA correction method was not more accurate than segmentaloptimisation for estimating scapula kinematics.
\end{abstract}

Keywords: Soft tissue artefact; Multibody kinematics optimisation; Upper limb; Shoulder; Kinematics model 


\section{$1 \quad$ 1. Introduction}

Soft tissue artefact (STA) remains one of the major issues when studying upper limb movements through the use of marker-based motion capture systems (Leardini et al., 2005). Indeed, STA up to $35^{\circ}$ in the humeral internal-external rotation (Cutti et al., 2005), and up to $8.7 \mathrm{~cm}$ at the scapula have been highlighted (Matsui et al., 2006). This makes translations and rotations of the scapula difficult to measure, especially with the anatomical marker set recommended by the International Society of Biomechanics (Wu et al., 2005), where markers are placed on angulus acromialis, trigonum spinae and angulus inferior to track the scapula.

To overcome this issue, a first approach can be based on the use of technical markers placed on the acromion. However, while results show a more accurate kinematics (Lempereur et al., 2014), the use of these additional markers is limited. Indeed, several studies restrained arm elevations to only $120^{\circ}$ due to the risk of markers occlusions, high measurement errors associated to deltoid bulging, and loss of contact between markers and acromion (Meskers et al., 2007; van Andel et al., 2009). Another approach can be to use post-acquisition data processing methods. Several methods minimising the deformation of a set of markers have been proposed as a way to correct STA (Cheze et al., 1995; Söderkvist and Wedin, 1993). Such segmental optimisation methods have been applied to the lower limb and were shown to be unable to correct rigid body displacement (Cappozzo et al., 2005; Dumas and Cheze, 2009). Thus, segmental optimisations were rarely applied to the upper limb (Lempereur et al., 2014, 2010; Prinold et al., 2011) . An alternative method, initially promoted for lower limb movement analysis (Andersen et al., 2009; Reinbolt et al., 2005), is called multibody kinematics optimisation (MKO). Using this approach, rigid body displacements are partially corrected, but the resulting joint kinematics is highly influenced by the set of joint models (Andersen et al., 2010). In particular, anatomically-based joint models result in a more 
accurate kinematics for the lower limb (Duprey et al., 2010). However, only a few studies have focused on the application of this approach to the upper limb (Dumas et al., 2016; Duprey et al., 2016 submitted).

The shoulder complex is commonly modelled as an open-loop kinematic chain with joints represented as three rotational degrees-of-freedom (DoF) joints (Högfors et al., 1991; Yang et al., 2009). However, regarding the glenohumeral joint, experimental studies reported in vivo upward translations up to $12.4 \mathrm{~mm}$ (Dal Maso et al., 2014; Graichen et al., 2000). Joint models including a 6-DoF or a parallel mechanism (El Habachi et al., 2015a) may partially solve this issue. Unfortunately, little is known about sternoclavicular and acromioclavicular joint translations, as only rotations have been investigated on these joints (Sahara et al., 2007). Furthermore, in presence of a kinematic chain, a recent study showed that joint kinematics is highly sensitive to the model parameters, especially to the clavicle length (El Habachi et al., 2015b). Thus, regarding the shoulder kinematic chain model, the level of biofidelity required to correct STA remains unknown.

In order to correct the above-mentioned limitations (i.e. markers occlusions, limited arm elevations, and sensitivity to model parameters), some authors proposed to include the scapulothoracic joint in the model, resulting in a closed-loop mechanism (i.e. fewer DoFs). This joint is often defined as a geometrical constraint, resulting in a contact between one to three fixed points belonging to the scapula with an ellipsoid representing the thorax (Garner and Pandy, 1999; Maurel, 1995; Tondu, 2005). This can be achieved through a geometrical constraint or by using an equivalent parallel mechanism (Ingram et al., 2016). However, a cadaveric study (Sah and Wang, 2009) showed that the scapula's area in contact with the thorax changes throughout a movement covering the complete arm reachable space. Models with fixed contact points between the scapula and the thorax may thus introduce systematic errors, and lead to penetration of the scapula into the thorax. On the other hand, a model only 
constraining the scapula to be tangent to the thorax should result in a more physiological scapulothoracic model (Blana et al., 2008; Tondu, 2007; van der Helm, 1994). As a result, it can be seen that various upper limb models have been developed in the literature (Duprey et al., 2016). However, results obtained with such a correction method are rarely compared to experimental reference data (Charbonnier et al., 2014; El Habachi et al., 2015a).

The aim of this study was thus to assess and compare different STA correction methods based on a segmental optimisation approach and on MKO. These optimisations were either associated with an open-loop or a closed-loop chain integrating different scapulothoracic joints (related to different kinematic constraints). The questions at stake here were: 1) Is MKO more efficient than segmental optimisation in STA correction for the upper limb and more specifically the scapula? 2) Should a closed-loop chain model be favoured over an open-loop chain model? 3) When using a closed-loop chain model, which scapulothoracic constraints should be preferred?

\section{Material and methods}

\subsection{Experimental data}

This study is a secondary use of a previous protocol, where only four participants were involved due to its invasiveness (Dal Maso et al., 2014). This protocol was approved by the local ethics committees of the University of Montreal (Canada) and the Karolinska Institutet (Sweden). Each participant signed an informed consent prior to this study. A detailed description of this protocol has been made available by Dal Maso et al. (2014). Briefly, intracortical pins were positioned distal to the medial attachment of the deltoid on the humerus, on the scapula spine, and on the superior part of the anterior concavity of the clavicle (Fig. 1). Rigid clusters of four (i.e. scapula, clavicle) or five (i.e. humerus) markers were connected firmly to the pins. Because STA were assumed to be small on the thorax 
compared to the distance between the markers, and because the fastening of pins is difficult in the sternum, cutaneous markers were used on this segment. These markers were positioned on the first and tenth thoracic vertebrae (T1, T10), incisura jugularis (IJ) and xiphoid process (XP), and were completed by the set of 28 technical markers used by Jackson et al. (2012) covering the whole upper limb (Fig. 1). To calibrate the model, an anatomical position and three series of functional movements were collected, which mobilised the sternoclavicular, acromioclavicular and glenohumeral DoFs, respectively (Jackson et al., 2012; Michaud et al., 2016). Then, the participants performed 10 repetitions of two tasks: abduction-adduction and flexion-extension of the arm. All movements were recorded using a system of 18 optoelectronic VICON ${ }^{\mathrm{TM}}$ cameras (Oxford Metrics Ltd., Oxford, UK). Marker occlusions were reported. As said in previous studies (Dal Maso et al., 2016, 2014), the scapula pin in two participants rotated slightly. Also, due to discomfort related to the invasiveness of the protocol, one other participant was not able to perform arm elevation movements above $120^{\circ}$.

Only the data of the remaining participant (male, 27 years, $57 \mathrm{~kg}, 165 \mathrm{~cm}$ ) were thus used for the subsequent analysis. Joint kinematics (i.e. rotations and translations) was extracted from the pin markers' trajectories and reported. The expression of the joint kinematics, hereafter called reference kinematics, followed the recommendations of the International Society of Biomechanics (Wu et al., 2005).

\subsection{Models}

A shoulder girdle model composed of three rigid segments (i.e. thorax, scapula, humerus) was defined with glenohumeral, acromioclavicular and sternoclavicular joints modelled as spherical joints. The clavicle was not modelled as a segment but as a kinematic constraint, i.e. a constant length between the scapula and the thorax (El Habachi et al., 2015a). The three joint centres were obtained using the SCoRE algorithm (Ehrig et al., 2006) applied on the three series of functional movements. For the clavicle and the arm, the Jackson et al.'s 
(2012) marker set was adopted. For the thorax, only the markers placed on the xiphoid process, incisura jugularis, and thoracic vertebrae ( $\mathrm{T} 1$ and $\mathrm{T} 10)$ were retained. For the scapula, the four markers placed on the acromioclavicular joint, and the markers placed on the angulus acromialis and on the lateral part of the scapula spine (i.e. two markers) were kept.

Then, three models of the scapulothoracic joint were defined (Tab. 1). For each of them, the same ellipsoid was used (Fig. 2). This ellipsoid was functionally determined using the displacements of five markers positioned on the scapula (i.e. angulus acromialis, trigonum spinae, angulus inferior and the two markers positioned on lateral part of the scapula spine) during the same movements as for the definition of the glenohumeral centre. The first two scapulothoracic models were defined respectively by one and two fixed contact points between this ellipsoid and the scapula (respectively termed as one-contact point or twocontact point models) (El Habachi et al., 2015a; Nikooyan et al., 2010) (see Appendix 1 for the definition of these contact points). The last model constrained the plane of the scapula to be tangent (in any point) to the ellipsoid (termed as tangent-contact model). This model was assumed to be more physiological since it allows the scapula to slide freely on the thorax with a moving contact point (see Appendix 1 for the definition of this point). In addition to these three scapulothoracic joint models, an open-loop mechanism was defined, i.e. without scapulothoracic joint (NoST). The penetration values of the scapula in the ellipsoid representing the thorax were reported for each model.

The authors also tested models without the clavicle constraints or with different glenohumeral constraints (i.e. 6-DoF and a parallel mechanism (El Habachi et al., 2015a) (Tab. 2)) for a total of 24 shoulder girdle models generated through the combinations of clavicle, glenohumeral and scapulothoracic joint constraints. The markers used in MKO (Fig. 1) were those placed on the thorax, on the acromioclavicular joint, on the angulus acromialis and on the lateral part of the scapula spine, as well as on the arm (i.e. seven 
124

125

128

markers) (Jackson et al., 2012). No marker on the clavicle was necessary since this segment was modelled as a constraint and not as a body segment.

\subsection{Comparison methods}

MKO was finally applied to the skin markers for the 24 shoulder girdle models in addition to the segmental optimisation. Their global performance was firstly estimated by expressing the root mean square error (RMSE) of the joint kinematics with respect to the reference kinematics for the scapulothoracic and the thoracohumeral kinematics. A $3^{\circ}$ RMSE difference between models was considered as clinically significant (Laudner et al., 2007; Tsai et al., 2003). An adaptation of the Bland and Altman graphs proposed by Krouwer (2008) was used for a detailed comparison of the scapulothoracic kinematics in which the error between each condition and the reference kinematics was plotted for each plane of rotation and for each task as a function of the reference thoracohumeral kinematics.

\section{Results}

Each model optimisation required less than 140s on a standard PC (CPU $3.3 \mathrm{GHz}$ RAM 8 Go) for a movement with approximately 470 frames. Marker occlusions varied between 0 and $13 \%$ of frames between the trials, the markers related to the acromioclavicular joint and the acromial tip being the most affected after $100^{\circ}$ of arm elevation. The pin data showed that the maximum translations at the sternoclavicular and acromioclavicular joints were $17.6 \mathrm{~mm}$ and $6 \mathrm{~mm}$ (averaged over the repetitions), respectively. Only results based on segmental optimisation and the variations of scapulothoracic constraints (for which the clavicle was modelled as a constant length and the glenohumeral as a spherical joint in MKO) are reported here. Results with the variations of clavicle and glenohumeral joint constraints are reported in Appendix 2. 


\subsection{Open loop versus closed loop}

Among all tasks and all DoFs, the RMSE range was $\left[1.1^{\circ} 3.3^{\circ}\right]$ when using segmental optimisation (Figs. 3 and 4). The use of the MKO increased the RMSE range to $\left[0.9^{\circ} 9.6^{\circ}\right]$. During the flexion task, both the open-loop and closed-loop (i.e. with scapulothoracic joint) mechanisms gave similar RMSE ranges, respectively $\left[\begin{array}{ll}0.9^{\circ} & 3.1^{\circ}\end{array}\right]$ and $\left[\begin{array}{ll}2.1^{\circ} & 2.8^{\circ}\end{array}\right]$. However, during the abduction task, the use of the closed-loop MKO reduced the RMSE from $9.6^{\circ}$ with open-loop to a RMSE range of $\left[1.4^{\circ} 4.1^{\circ}\right]$ for the posterior anterior tilt, and from $7.7^{\circ}$ to $\left[1.0^{\circ}\right.$ $3.3^{\circ}$ ] for the protraction retraction. A similar RMSE range was found for the downwardupward rotation with $2.9^{\circ}$ for the open-loop versus a range of $\left[2.0^{\circ} 2.7^{\circ}\right]$ for the closed-loop MKO. With respect to segmental optimisation, all RMSE differences were higher than $2^{\circ}$ for the open-loop MKO, but systematically lower for the closed-loop MKO.

\subsection{Effect of scapulothoracic joints}

When considering the difference between the different scapulothoracic models, no clinically-relevant difference $\left(3^{\circ}\right)$ was observed between the RMSE range for the onecontact point $\left(\left[0.9^{\circ} 4.1^{\circ}\right]\right)$, tangent-contact $\left(\left[1.0^{\circ} 3.6^{\circ}\right]\right)$ or two-contact point models $\left(\left[1.0^{\circ}\right.\right.$ $\left.2.8^{\circ}\right]$ ). Nevertheless, except for the posterior tilt during flexion, the two-contact point model tends to give the lowest RMSE. Overall, the RMSE in segmental optimisation tends to be lower than those in MKO, except for the two-contact point model for the anterior-posterior tilt and the protraction-retraction during the abduction and flexion tasks, and for the one-contact point and tangent-contact models for the anterior-posterior tilt during the flexion task.

\subsection{Scapula-Thorax interpenetration}

When considering the scapula penetration (Fig. 5), the one and two-contact point models give rise to a penetration in the ellipsoid up to $7.3 \mathrm{~mm}$ and $6.3 \mathrm{~mm}$, respectively, whereas the tangent-contact model, by definition, did not generate any penetration. Both the 
segmental optimisation and reference data created a systematic positive offset between the

172 ellipsoid and the scapula up to $14 \mathrm{~mm}$ and $11 \mathrm{~mm}$, respectively.

\section{4. Discussion}

174 Modelling the upper limb skeleton for MKO is a delicate compromise between biofidelity of

175 the kinematic chain, and ability to estimate coupling DoF displacements using experimental skin markers to correct STA. Our objective was to assess and compare, on the scapula kinematics, the effect of different STA correction methods based on segmental or multibody kinematics (i.e. MKO) optimisations with various joint models. The main findings are that 1) segmental optimisation led to accurate scapula kinematics (RMSE $\leq 3.3^{\circ}$ on each axis)

180 whatever the arm elevation angle and motion; 2) when using MKO, a twofold STA correction was achieved by modelling the scapulothoracic joint; but 3) the choice of the scapulothoracic joint model had little effect on the STA correction.

The present study is a case report based on a participant of normal body mass index

$184(\mathrm{BMI}=20.94)$. Only one of four participants was selected for his ability to reach maximal range of motion (Fig. 4, $160^{\circ}$ of arm elevation) without discomfort and intracortical pin rotation. Findings should thus be interpreted with caution and be confirmed by future - less

187 accurate but non-invasive - studies based on a scapula palpator (Johnson et al., 1993), and with a larger sample size. Nevertheless, intracortical pin measurement is considered as a gold standard as dynamic movements (free of palpation errors) can be recorded; unlike 190 measurement using a scapula palpator. Markers placed on the spine of the scapula, in addition to those on the acromion,

192 resulted in an unexpected accuracy of the segmental optimisation, though the marker

193 locations close to the intracortical pin could have reduced the STA. Similarly, Bourne et al. 194 (2011) obtained a RMSE ranged between $2^{\circ}$ and $5^{\circ}$ using a multiple calibration correction. 
However, without correction, a higher RMSE range ([5.5 9. $\left.\left.{ }^{\circ}\right]\right)$ was found. The different

196 marker sets between studies may partially explain this phenomenon. In the present study, skin markers were preferred to an acromial cluster (with sticks) as commonly used (Brochard et al., 2011; De Baets et al., 2013; Karduna et al., 2001; Lempereur et al., 2010; van Andel et al., 2009) for three experimental reasons: 1) the acromial cluster may interfere with the pins but also the neck in maximal elevation; 2) the acromial cluster may vibrate during fast motions (Ramsey et al., 2003); and 3) a rigid cluster (similarly to an electromagnetic sensor) shows redundancy since each marker undergoes the same STA rototranslation. Indeed, in the studies of Brochard et al. (2011) and van Andel et. (2009), errors up to $11^{\circ}$ and $8.5^{\circ}$ were found without correction, respectively, and these errors increased after $90^{\circ}$ of arm elevation. For maximal elevations, amplitude errors up to $16^{\circ}$ and up to $20^{\circ}$ were obtained by Lempereur et al. (2010) and Karduna et al. (2001), respectively. Consequently, as elevations up to $160^{\circ}$ were tested in our study, our marker set was thought to be more adapted for measuring the scapula movement.

The same marker set used in open-loop MKO gave a four-fold error in scapula kinematics, probably due to the strict constraint related to the clavicle constant length. Indeed, glenohumeral joint models (i.e. spherical, parallel or free joint) showed no effect on the kinematics (Appendix 2). While segmental optimisation leads to apparent joint dislocation,

213 MKO can strictly prevent the joint from any translation. Nevertheless, similarly to the 214 glenohumeral joint (Dal Maso et al., 2014; Graichen et al., 2000), sternoclavicular and acromioclavicular joints are not perfect ball-and-sockets joints. In these two non-congruent 216 joints, which are mainly maintained by a series of ligaments, pin-based kinematics 217 highlighted translations up to 17 and $6 \mathrm{~mm}$, respectively. Compared to the estimated clavicle 218 length $(120 \mathrm{~mm})$, such translations are not negligible and could explain the lower STA error 219 obtained with the segmental optimisation relative to the open-loop MKO. With a different 
approach (gold standard bone kinematics versus sensitivity analysis), the present study

221 reinforces the findings of El-Habachi et al. (2015b) stating that the scapular girdle kinematics

222 is affected by the model parameters, especially the clavicle length. In the present work, the 223 sternoclavicular and acromioclavicular joint centres were located independently using a

224 functional approach (Ehrig et al., 2006). However, as shown by Michaud et al. (2016), skin 225 markers cannot accurately locate sternoclavicular and acromioclavicular joint centres. In a 226 similar manner, the functional ellipsoid used in this study might not be adapted for MKO. 227 Indeed, a systematic positive offset between the ellipsoid and the scapula was obtained when 228 using reference data, whereas the use of a scapulothoracic joint tended to lead to 229 interpenetration. A better approach would be to estimate both the clavicle length and ellipsoid 230 parameters concomitantly with the kinematics reconstruction, using the algorithms proposed 231 by Reinbolt et al. (2005) and Andersen et al. (2010).

232 The scapular girdle with a scapulothoracic joint modelled as a point-ellipsoid contact has been 233 introduced by Veeger (1991) in the early 90's in a musculoskeletal model in order to obtain 234 realistic movements of the scapula. Several kinematic studies flowed from this innovative 235 model to improve the ellipsoid definition (Bolsterlee et al., 2014; Prinold et al., 2011) and to 236 define the best contact points between the scapula and the thorax (Berthonnaud et al., 2005; 237 Maurel, 1995; Tondu, 2005). Hence, the scapular girdle was modelled as a closed-loop 238 mechanism with small dimensions, and several experimental issues were related to the 239 identification of its geometry due to large STA. A tangential contact between the scapula and 240 the thorax, avoiding penetration of the scapula into the thorax and allowing a moving contact 241 point between these structures, has been introduced in this study. However, the resulting 242 kinematics showed no advantage of this "anatomical-like" constraint. The model allowing a 243 moving contact point (tangent-contact model) between the scapula and the ellipsoid 
representing the thorax provides a RMSE similar to the model with one fixed contact point and slightly higher than the model with two fixed contact points.

Those differences might be due to the fact that the one-contact point and the tangent-contact scapulothoracic joint models have more degrees of freedom (6 DoFs) than the two-contact point models (5 DoFs), thus enlarging the possibilities of bone positioning. Whereas the above mentioned RMSE results do not prove any gain of using a tangent-contact scapulothoracic joint model in MKO for correcting STA, this model has the advantage of being as close as possible to anatomy (Sah and Wang, 2009). Besides avoiding interpenetrations of bones, having a mobile contact point moving with respect to the scapula could enhance the prediction of muscular moment arms, and thus help obtaining more realistic dynamic and musculoskeletal models. It might also be more adapted for pathological populations such as for patients suffering from scapula dyskinesis (e.g. scapula allata), where the contact between the thorax and some part of the scapula may be lost. Consequently, it seems that the tangent-contact joint model should be considered for further development.

\section{Conclusion}

MKO is not more accurate than segmental optimisation for estimating scapula kinematics in the presence of STA. Consequently, we recommend using segmental optimisation with individual markers placed on the acromion and along the spine of the scapula. Indeed, this approach provides accurate results, is easier to implement than $\mathrm{MKO}$ and is not affected by geometrical parameters. However, when a simplified kinematic chain without joint translation is required (e.g. in musculoskeletal modelling), the scapulothoracic joint should be included. In particular, in line with previous experimental data (Sah and Wang, 2009), a tangential scapulothoracic model allowing a mobile contact point could be recommended. 


\section{Acknowledgements}

269 This work has been funded by the Luxembourg National Research Fund (Grant AFR-PhD

270 3972379).

\section{Conflict of Interest Statement}

272 The authors hereby affirm that the study does not raise any conflict of interest.

273 


\section{References}

275

276

277

278

279

280

281

282

283

284

285

286

287

288

289

290

291

292

293

294

295

296

297

298

299

300

301

302

303

304

305

306

307

308

309

310

311

312

313

Andersen, M.S., Damsgaard, M., MacWilliams, B., Rasmussen, J., 2010. A computationally efficient optimisation-based method for parameter identification of kinematically determinate and over-determinate biomechanical systems. Comput. Methods Biomech. Biomed. Engin. 13, 171-183.

Andersen, M.S., Damsgaard, M., Rasmussen, J., 2009. Kinematic analysis of overdeterminate biomechanical systems. Comput. Methods Biomech. Biomed. Engin. 12, 371-84. doi:10.1080/10255840802459412

Berthonnaud, E., Herzberg, G., Zhao, K.D., An, K.N., Dimnet, J., 2005. Three-dimensional in vivo displacements of the shoulder complex from biplanar radiography. Surg. Radiol. Anat. 27, 214-222.

Blana, D., Hincapie, J.G., Chadwick, E.K., Kirsch, R.F., 2008. A musculoskeletal model of the upper extremity for use in the development of neuroprosthetic systems. J. Biomech. 41, 1714-1721. doi:10.1016/j.jbiomech.2008.03.001

Bolsterlee, B., Veeger, H.E.J., van der Helm, F.C.T., 2014. Modelling clavicular and scapular kinematics: from measurement to simulation. Med. Biol. Eng. Comput. 52, 283-291. doi:10.1007/s11517-013-1065-2

Bourne, D.A., Choo, A.M., Regan, W.D., MacIntyre, D.L., Oxland, T.R., 2011. The Placement of Skin Surface Markers for Non-Invasive Measurement of Scapular Kinematics Affects Accuracy and Reliability. Ann. Biomed. Eng. 39, 777-785. doi:10.1007/s10439-010-0185-1

Brochard, S., Lempereur, M., Rémy-Néris, O., 2011. Accuracy and reliability of three methods of recording scapular motion using reflective skin markers. Proc. Inst. Mech. Eng. Part H J. Eng. Med. 225, 100-105. doi:10.1243/09544119JEIM830

Cappozzo, A., Della Croce, U., Leardini, A., Chiari, L., 2005. Human movement analysis using stereophotogrammetry. Part 1: theoretical background. Gait Posture 21, 186-96. doi:10.1016/j.gaitpost.2004.01.010

Charbonnier, C., Chagué, S., Kolo, F.C., Chow, J.C.K., Lädermann, a, 2014. A patientspecific measurement technique to model shoulder joint kinematics. Orthop. Traumatol. Surg. Res. 100, 715-9. doi:10.1016/j.otsr.2014.06.015

Cheze, L., Fregly, B., Dimnet, J., 1995. A solidification procedure to facilitate kinematic analyses based on video system data. J. Biomech. 28, 879-884.

Cutti, A.G., Paolini, G., Troncossi, M., Cappello, A., Davalli, A., 2005. Soft tissue artefact assessment in humeral axial rotation. Gait Posture 21, 341-9. doi:10.1016/j.gaitpost.2004.04.001

Dal Maso, F., Blache, Y., Raison, M., Lundberg, A., Begon, M., 2016. Glenohumeral joint kinematics measured by intracortical pins, reflective markers, and computed tomography: A novel technique to assess acromiohumeral distance. J. Electromyogr. Kinesiol. 29, 4-11. doi:10.1016/j.jelekin.2015.07.008

Dal Maso, F., Raison, M., Lundberg, A., Arndt, A., Begon, M., 2014. Coupling between 3D 
displacements and rotations at the glenohumeral joint during dynamic tasks in healthy participants. Clin. Biomech.

(Bristol, Avon)

29 , $1048-55$. doi:10.1016/j.clinbiomech.2014.08.006

De Baets, L., Van Deun, S., Desloovere, K., Jaspers, E., 2013. Dynamic scapular movement analysis: Is it feasible and reliable in stroke patients during arm elevation? PLoS One 8, e79046. doi:10.1371/journal.pone.0079046

Dumas, R., Andersen, M.S., Begon, M., 2016. What are the joint models used in multibody kinematic optimisation for the estimation of human joint kinematics? a review. 4th Int. Digit. Hum. Model. Symp. 1-5.

Dumas, R., Cheze, L., 2009. Soft tissue artifact compensation by linear 3D interpolation and approximation methods. J. Biomech. 42, 2214-7. doi:10.1016/j.jbiomech.2009.06.006

Duprey, S., Cheze, L., Dumas, R., 2010. Influence of joint constraints on lower limb kinematics estimation from skin markers using global optimization. J. Biomech. 43, 2858-62. doi:10.1016/j.jbiomech.2010.06.010

Duprey, S., Naaim, A., Moissenet, F., Begon, M., Cheze, L., 2016. Kinematic models of the upper limb joints for multibody kinematic optimisation: an overview. J. Biomech.

Ehrig, R.M., Taylor, W.R., Duda, G.N., Heller, M.O., 2006. A survey of formal methods for determining the centre of rotation of ball joints. J. Biomech. 39, 2798-809. doi:10.1016/j.jbiomech.2005.10.002

El Habachi, A., Duprey, S., Cheze, L., Dumas, R., 2015a. A parallel mechanism of the shoulder-application to multi-body optimisation. Multibody Syst. Dyn. 33, 439-451. doi:10.1007/s11044-014-9418-7

El Habachi, A., Moissenet, F., Duprey, S., Cheze, L., Dumas, R., 2015b. Global sensitivity analysis of the joint kinematics during gait to the parameters of a lower limb multi-body model. Med. Biol. Eng. Comput. 655-667. doi:10.1007/s11517-015-1269-8

Garner, B. a., Pandy, M.G., 1999. A Kinematic Model of the Upper Limb Based on the Visible Human Project (VHP) Image Dataset. Comput. Methods Biomech. Biomed. Engin. 2, 107-124. doi:10.1080/10255849908907981

Graichen, H., Stammberger, T., Bonel, H., Karl-Hans Englmeier, Reiser, M., Eckstein, F., 2000. Glenohumeral translation during active and passive elevation of the shoulder - a 3D open-MRI study. J. Biomech. 33, 609-613. doi:10.1016/S0021-9290(99)00209-2

Högfors, C., Peterson, B., Sigholm, G., Herberts, P., 1991. Biomechanical model of the human shoulder joint--II. The shoulder rhythm. J. Biomech. 24, 699-709.

Ingram, D., Engelhardt, C., Farron, A., Terrier, A., Müllhaupt, P., 2016. Modelling of the human shoulder as a parallel mechanism without constraints. Mech. Mach. Theory 100, 120-137. doi:10.1016/j.mechmachtheory.2016.02.004

Jackson, M., Michaud, B., Tétreault, P., Begon, M., 2012. Improvements in measuring shoulder joint kinematics. J. Biomech. 45, 2180-3. doi:10.1016/j.jbiomech.2012.05.042

Johnson, G.R., Stuart, P.R., Mitchell, S., 1993. A method for the measurement of threedimensional scapular movement. Clin. Biomech. (Bristol, Avon) 8, 269-73. 
355

356

357

358

359

360

361

362

Karduna, A.R., McClure, P.W., Michener, L.A., Sennett, B., 2001. Dynamic measurements of three-dimensional scapular kinematics: a validation study., Journal of Biomechanical Engineering.

Krouwer, J.S., 2008. Why Bland-Altman plots should use $\mathrm{X}$, not $(\mathrm{Y}+\mathrm{X}) / 2$ when $\mathrm{X}$ is a reference method. Stat. Med. 27, 778-80. doi:10.1002/sim.3086

Laudner, K.G., Stanek, J.M., Meister, K., 2007. Differences in scapular upward rotation between baseball pitchers and position players. Am. J. Sports Med. 35, 2091-5. doi: $10.1177 / 0363546507305098$

Leardini, A., Chiari, L., Della Croce, U., Cappozzo, A., 2005. Human movement analysis using stereophotogrammetry. Part 3. Soft tissue artifact assessment and compensation. Gait Posture 21, 212-25. doi:10.1016/j.gaitpost.2004.05.002

Lempereur, M., Brochard, S., Burdin, V., Rémy-néris, O., 2010. Difference between palpation and optoelectronics recording of scapular motion. Comput. Methods Biomech. Biomed. Engin. 13, 49-57. doi:10.1080/10255840903014959

Lempereur, M., Brochard, S., Leboeuf, F., Rémy-Néris, O., 2014. Validity and reliability of 3D marker based scapular motion analysis: A systematic review. J. Biomech. doi:10.1016/j.jbiomech.2014.04.028

Matsui, K., Shimada, K., Andrew, P.D., 2006. Deviation of skin marker from bone target during movement of the scapula. J. Orthop. Sci. 11, 180-4. doi:10.1007/s00776-005$1000-\mathrm{y}$

Maurel, W., 1995. 3D modeling of the human upper limb including the biomechanics of joints, muscles and soft tissues. EPFL.

Maurel, W., Thalmann, D., 1999. A Case Study on Human Upper Limb Modelling for Dynamic Simulation. Comput. Methods Biomech. Biomed. Engin. doi:10.1080/10255849908907979

Meskers, C.G.M., van de Sande, M. a J., de Groot, J.H., 2007. Comparison between tripod and skin-fixed recording of scapular motion. J. Biomech. 40, 941-6. doi:10.1016/j.jbiomech.2006.02.011

Michaud, B., Jackson, M., Arndt, A., Lundberg, A., Begon, M., 2016. Determining in vivo sternoclavicular, acromioclavicular and glenohumeral joint centre locations from skin markers, CT-scans and intracortical pins: A comparison study. Med. Eng. Phys. 38, 290296. doi:10.1016/j.medengphy.2015.12.004

Nikooyan, a a, Veeger, H.E.J., Westerhoff, P., Graichen, F., Bergmann, G., van der Helm, F.C.T., 2010. Validation of the Delft Shoulder and Elbow Model using in-vivo glenohumeral joint contact forces. J. Biomech. 43, 3007-14. doi:10.1016/j.jbiomech.2010.06.015

Prinold, J.A.I., Shaheen, A.F., Bull, A.M.J., 2011. Skin-fixed scapula trackers: A comparison of two dynamic methods across a range of calibration positions. J. Biomech. 44, 2004 2007. 
Quental, C., Folgado, J., Ambrósio, J., Monteiro, J., 2012. A multibody biomechanical model of the upper limb including the shoulder girdle. Multibody Syst. Dyn. 28, 83-108. doi:10.1007/s11044-011-9297-0

Ramsey, D.K., Wretenberg, P.F., Benoit, D.L., Lamontagne, M., Németh, G., 2003. Methodological concerns using intra-cortical pins to measure tibiofemoral kinematics. Knee Surg. Sports Traumatol. Arthrosc. 11, 344-349. doi:10.1007/s00167-003-0388-1

Reinbolt, J. a, Schutte, J.F., Fregly, B.J., Koh, B. Il, Haftka, R.T., George, A.D., Mitchell, K.H., 2005. Determination of patient-specific multi-joint kinematic models through twolevel optimization. J. Biomech. 38, 621-6. doi:10.1016/j.jbiomech.2004.03.031

Sah, S., Wang, X., 2009. Determination of geometric constraints between the ribcage and scapula in the shoulder complex : a cadaver study. Comput. Methods Biomech. Biomed. Engin. 12, 223-224. doi:10.1080/10255840903093979

Sahara, W., Sugamoto, K., Murai, M., Yoshikawa, H., 2007. Three-dimensional clavicular and acromioclavicular rotations during arm abduction using vertically open MRI. J. Orthop. Res. 25, 1243-9. doi:10.1002/jor.20407

Söderkvist, I., Wedin, P.-A., 1993. Determining the movements of the skeleton using wellconfigured markers. J. Biomech. 26, 1473-1477.

Tondu, B., 2007. Estimating shoulder-complex mobility. Appl. Bionics Biomech. 4, 19-29. doi: $10.1080 / 11762320701403922$

Tondu, B., 2005. Modelling of the shoulder complex and application the design of upper extremities for humanoid robots. 5th IEEERAS Int. Conf. Humanoid Robot. 2005. doi:10.1109/ICHR.2005.1573586

Tsai, N.-T., McClure, P.W., Karduna, A.R., 2003. Effects of muscle fatigue on 3-dimensional scapular kinematics. Arch. Phys. Med. Rehabil. 84, 1000-1005. doi:10.1016/S00039993(03)00127-8

van Andel, C., van Hutten, K., Eversdijk, M., Veeger, D., Harlaar, J., 2009. Recording scapular motion using an acromion marker cluster. Gait Posture 29, 123-8. doi:10.1016/j.gaitpost.2008.07.012

van der Helm, F.C., 1994. A finite element musculoskeletal model of the shoulder mechanism. J. Biomech. 27, 551-69.

Veeger, H.E.J., Van Der Helm, F.C.T., Van Der Woude, L.H. V, Pronk, G.M., Rozendal, R.H., 1991. Inertia and muscle contraction parameters for musculoskeletal modelling of the shoulder mechanism. J. ... 24, 615-629.

Wu, G., van der Helm, F.C.T., Veeger, H.E.J., Makhsous, M., Van Roy, P., Anglin, C., Nagels, J., Karduna, A.R., McQuade, K., Wang, X., Werner, F.W., Buchholz, B., 2005. ISB recommendation on definitions of joint coordinate systems of various joints for the reporting of human joint motion-Part II: shoulder, elbow, wrist and hand. J. Biomech. 38, 981-992. doi:10.1016/j.jbiomech.2004.05.042

Yang, J.J., Feng, X., Xiang, Y., Kim, J.H., Rajulu, S., 2009. Determining the threedimensional relation between the skeletal elements of the human shoulder complex. J. Biomech. 42, 1762-7. doi:10.1016/j.jbiomech.2009.04.048 
Figures

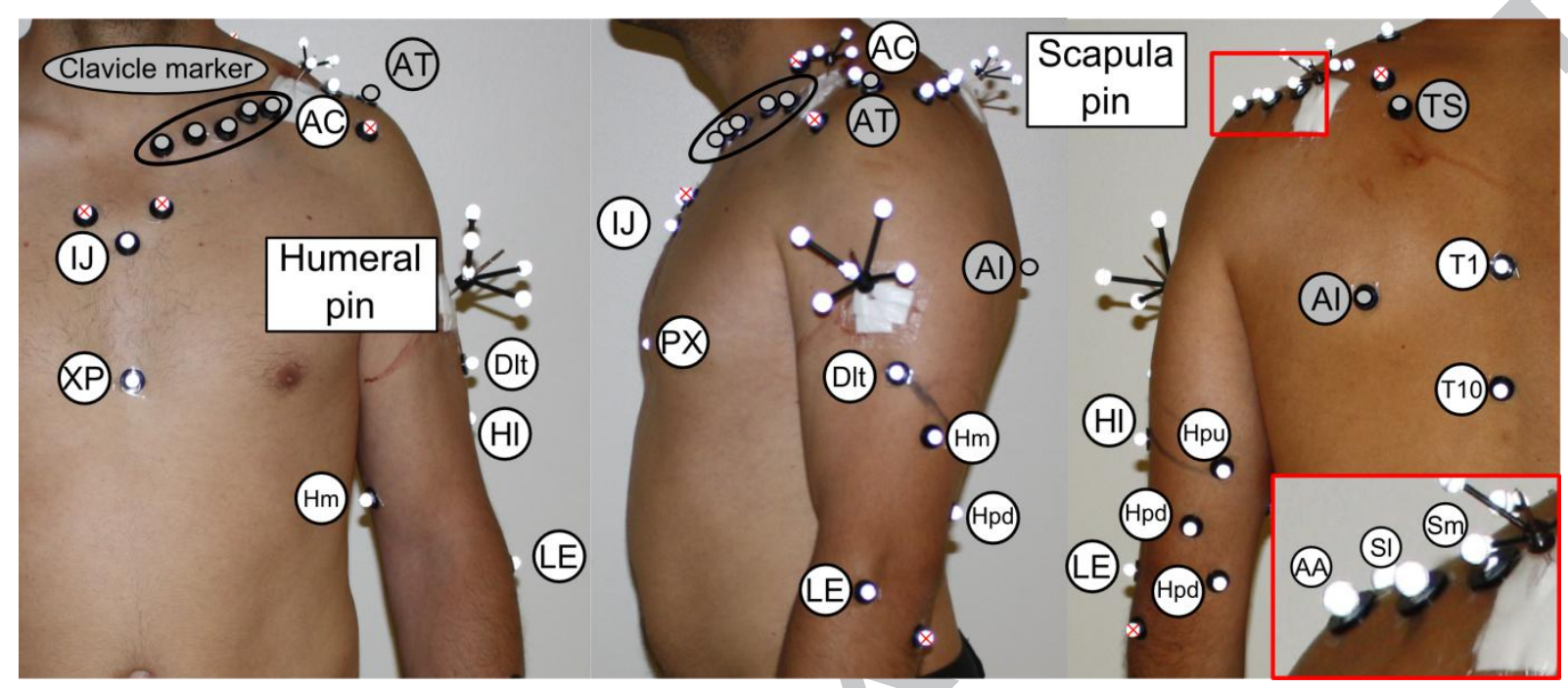

Figure 1: Positions of the pins and markers on the subjects. (IJ: incisura jugularis, XP: xiphoid process, T1: first thoracic vertebrae, T10: tenth thoracic vertebrae, AC: acromioclavicular joint, AT: acromial tip, SI and Sm: lateral scapula spine, TS: trigonum spinae, AI: angulus inferior, LE: lateral epicondyle, other markers are technical markers which are positioned in order to minimise soft tissue artefacts). Markers with a red cross were not used in this study, grey markers were used only for the geometrical construction of the model, and white markers were also used for the multibody kinematic optimisation. 


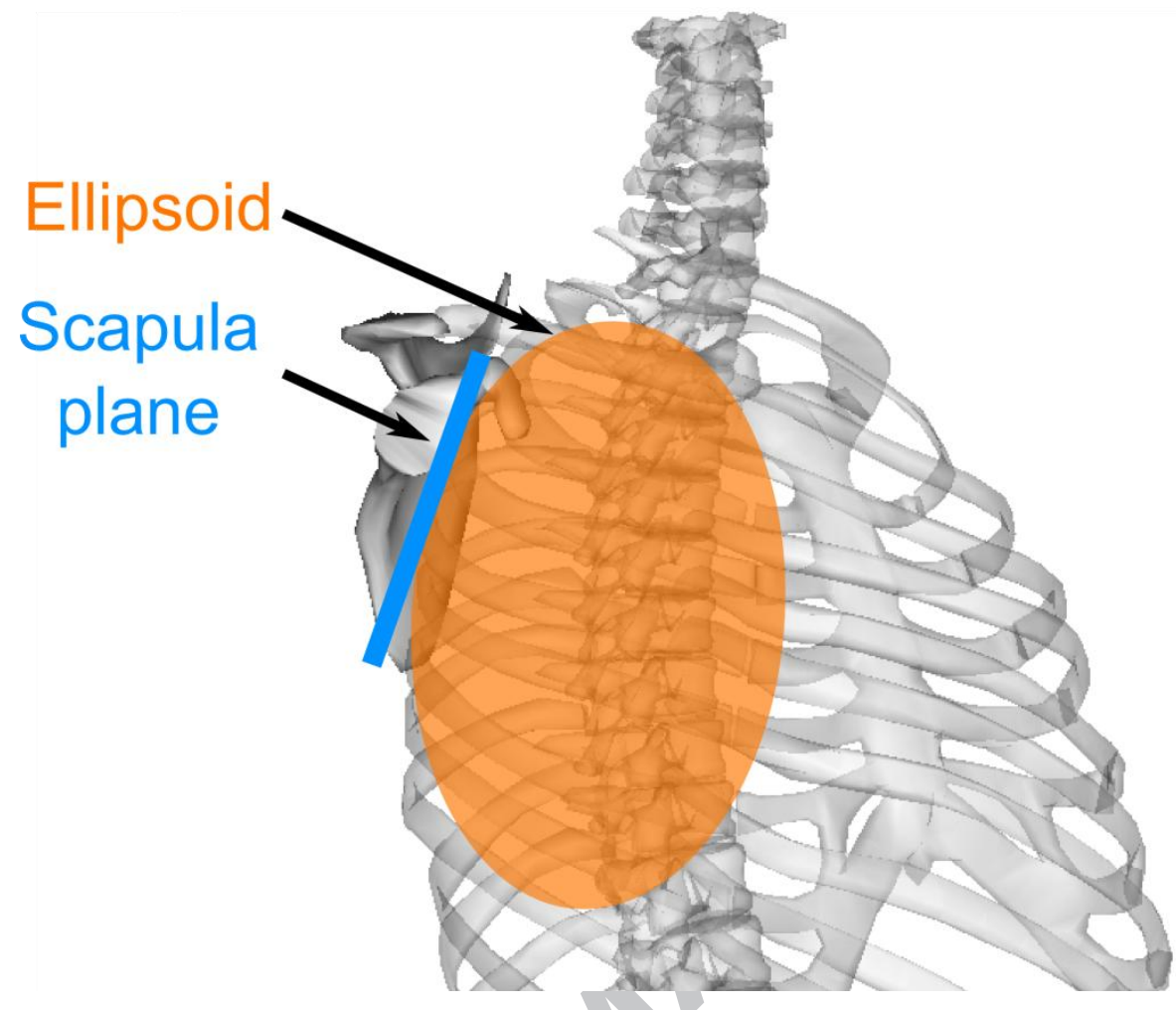

Figure 2: Schema of the ellipsoid used for the scapulothoracic constraint 


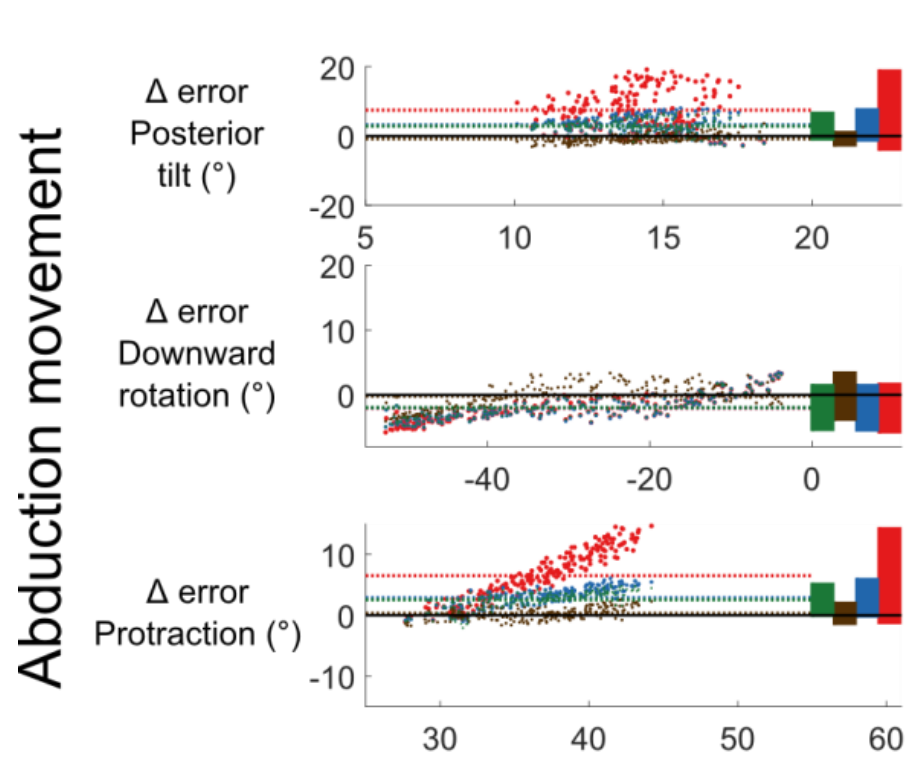

\section{RMSE}

RMSE
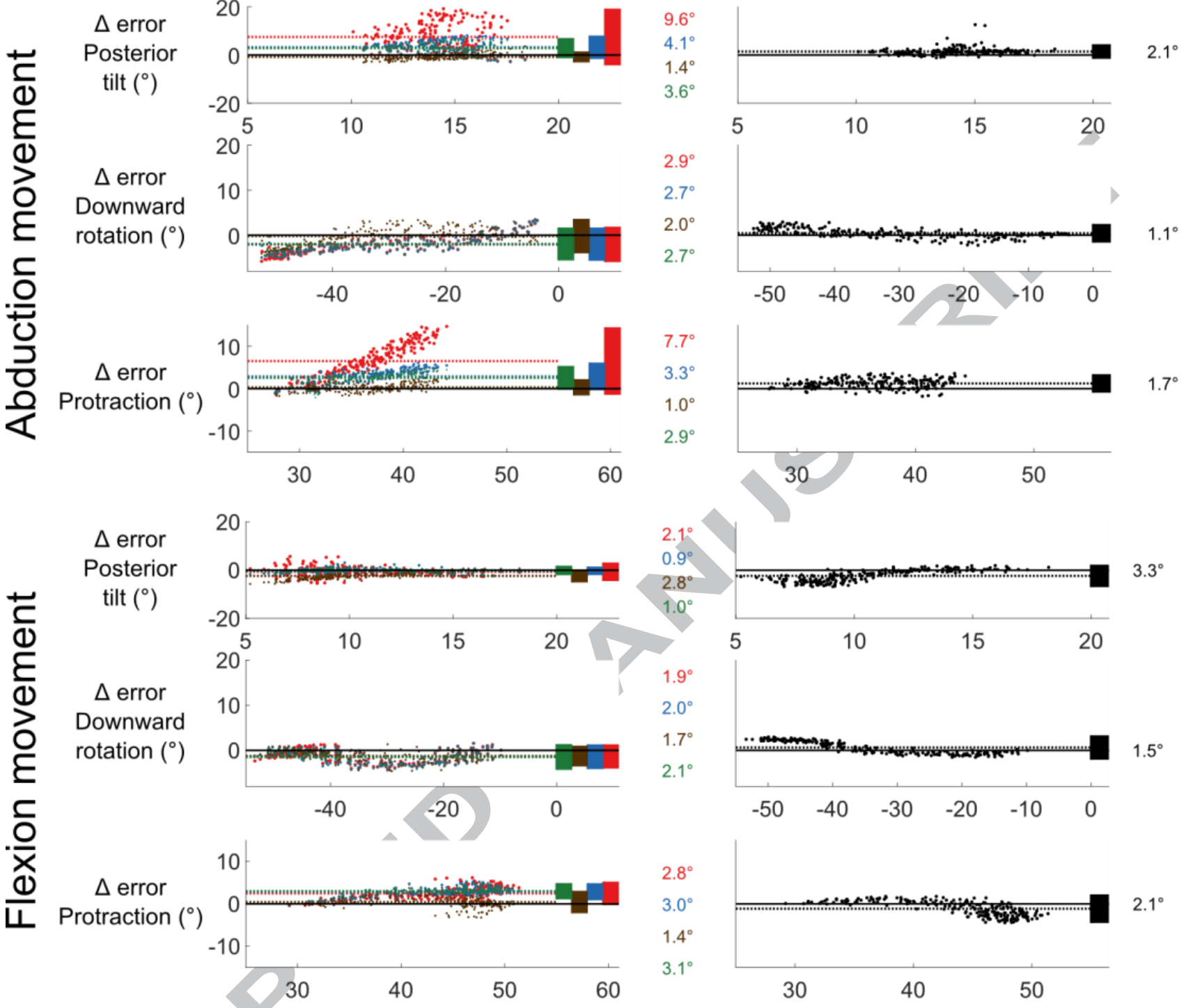

Segmental optimisation

reference angular displacement $\left({ }^{\circ}\right)$

Open loop (NoST)

Closed loop-ST: 1 contact point

Closed loop-ST: 2 contact points

Closed loop-ST: tangent to an ellipsoid

Figure 3: Bland-Altman plots (angular error with respect to reference kinematics) during the abduction and flexion movements for the four different multibody kinematics optimisation models (left) and the segmental optimisation (right). 

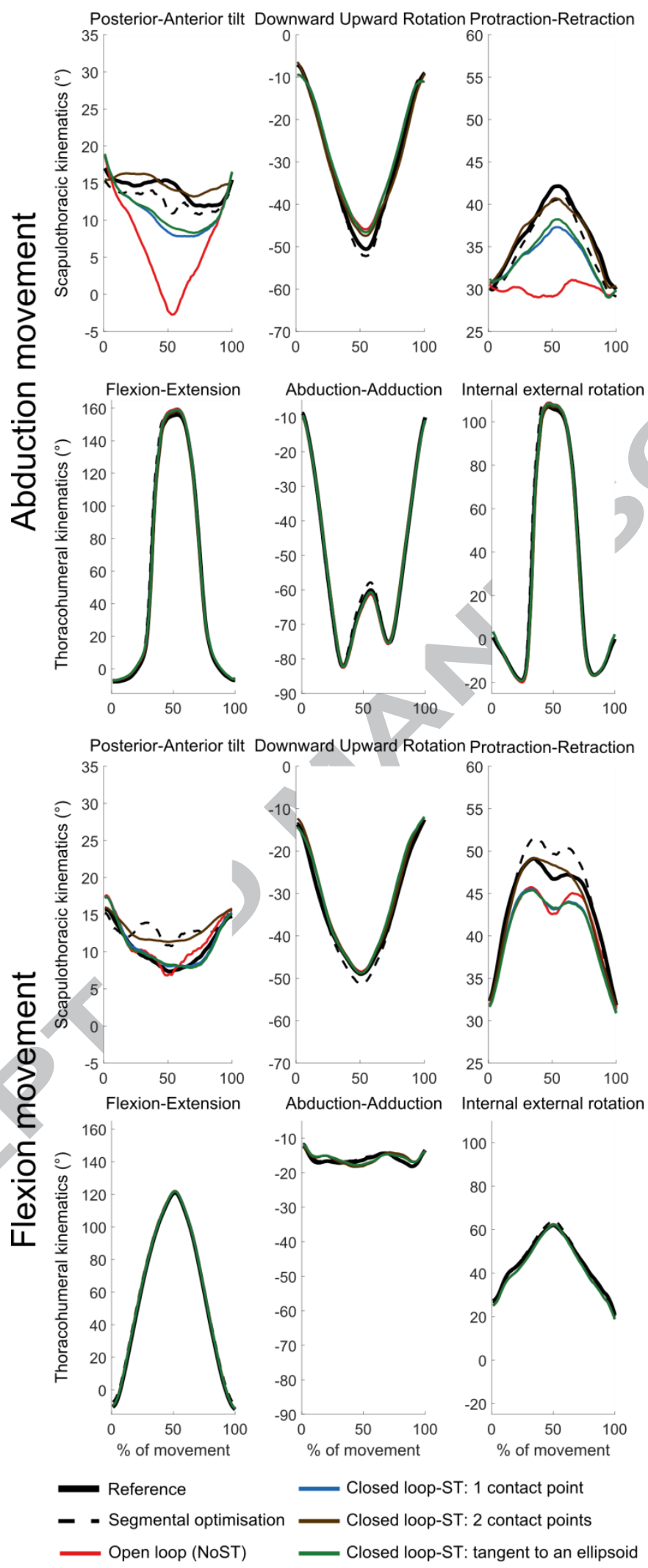

Figure 4: Thoracohumeral and Scapulothoracic kinematics for the abduction and flexion movements for the reference data, with segmental optimisation and with the four different multibody kinematics optimisation models. 
Flexion movement Abduction movement
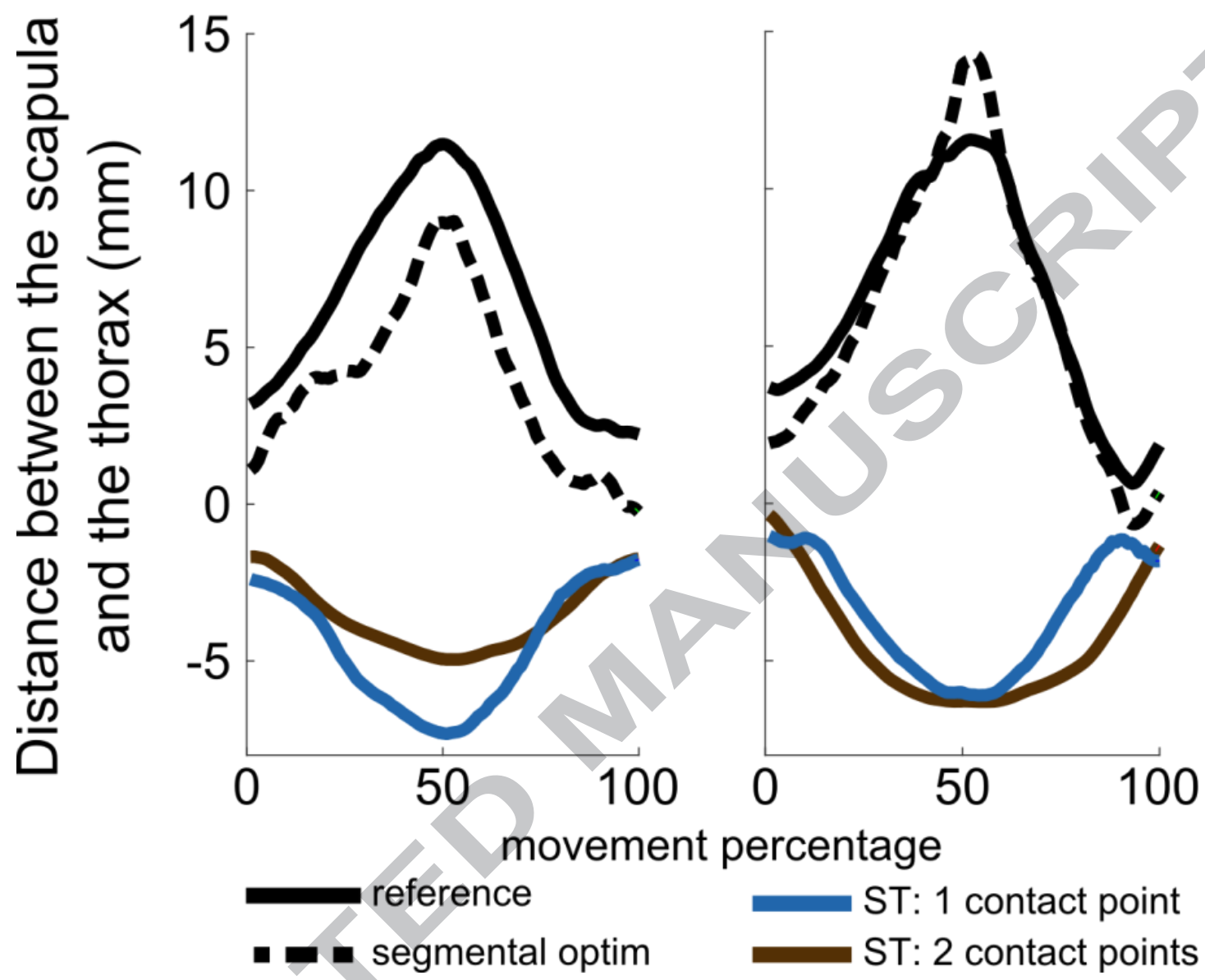

Figure 5: Distance between the scapula and the ellipsoid representing the thorax (in $\mathrm{mm})$, for the abduction and flexion movements with segmental optimisation and with one and two contact point scapulothoracic models. 


\section{Tables}

Table 1: Scapulothoracic joint models used for the multibody kinematics optimisation

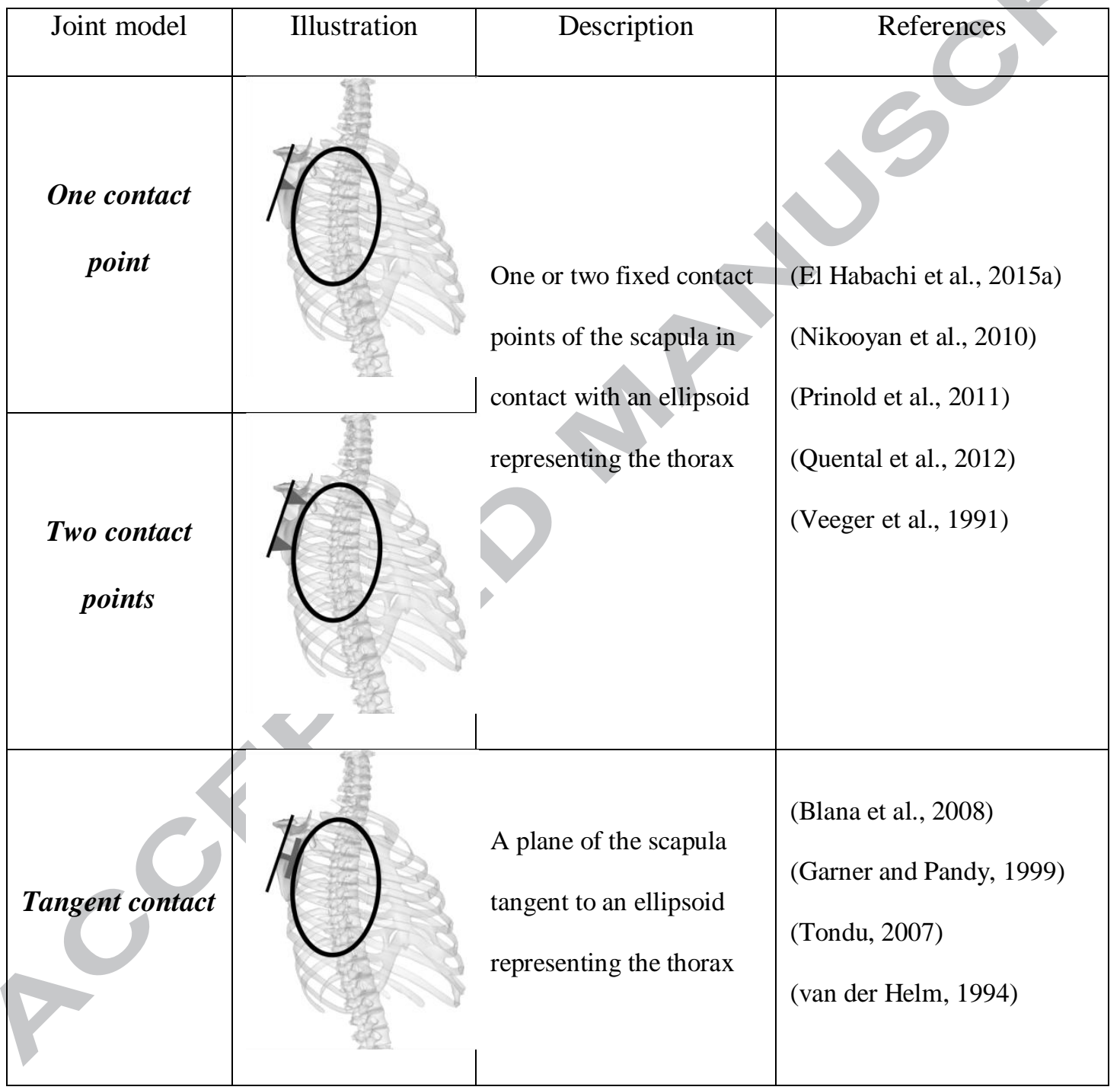


Table 2: Glenohumeral joint models used for the multibody kinematics optimisation

\begin{tabular}{|c|c|c|c|}
\hline Joint model & Illustration & Description & References \\
\hline Spherical & & $\begin{array}{l}\text { A spherical joint between } \\
\text { the scapula and the } \\
\text { humerus at the centre of } \\
\text { the humeral head }\end{array}$ & $\begin{array}{l}\text { (Garner and Pandy, 1999) } \\
\text { (Högfors et al., 1991) } \\
\text { (Maurel and Thalmann, 1999) }\end{array}$ \\
\hline $\begin{array}{l}\text { Parallel } \\
\text { mechanism } \\
\text { (Sphere-on- } \\
\text { sphere) }\end{array}$ & & $\begin{array}{l}\text { A link between the centre } \\
\text { of the glenoid and the } \\
\text { humeral head }\end{array}$ & (El Habachi et al., 2015a) \\
\hline
\end{tabular}




\section{Appendix 1}

Two scapulothoracic models were defined using one and two fixed contact points between an ellipsoid representing the thorax and the scapula respectively termed as one-contact point or two-contact point models. The points used in these two constraints are a projection of selected scapula landmarks on the ellipsoid according to the normal to the scapula plane during a static acquisition in the reference posture. The considered scapula landmarks are the centroid of angulus acromialis, trigonum spinae and angulus inferior, for the one contact point's model, or trigonum spinae and angulus inferior for the two contact points' model.

The plane of the scapula used for the tangent to an ellipsoid model, termed as tangent-contact model, is also defined during the static acquisition. This plane has the same normal as the scapula plane (defined by the angulus acromialis, trigonum spinae and angulus inferior markers) and passes through the ellipsoid point where the ellipsoid normal is the same as that of the scapula plane. This plane is then tangent to the ellipsoid in static position. This tangent to an ellipsoid constraint allows the virtual plane to rotate and glide in every direction maintaining always one moving contact point with the ellipsoid. 


\section{Appendix 2}

In addition to the four scapulothoracic joint models (free joint, one and two scapulothoracic contact points and tangent to an ellipsoid), different glenohumeral (free joint, spherical joint and parallel joint) and clavicle models (free joint and constant length) were considered in this work. The Bland-Altman plot for all the 24 model combinations and the segmental optimisation are displayed for the two movements. 


\section{Flexion movement}

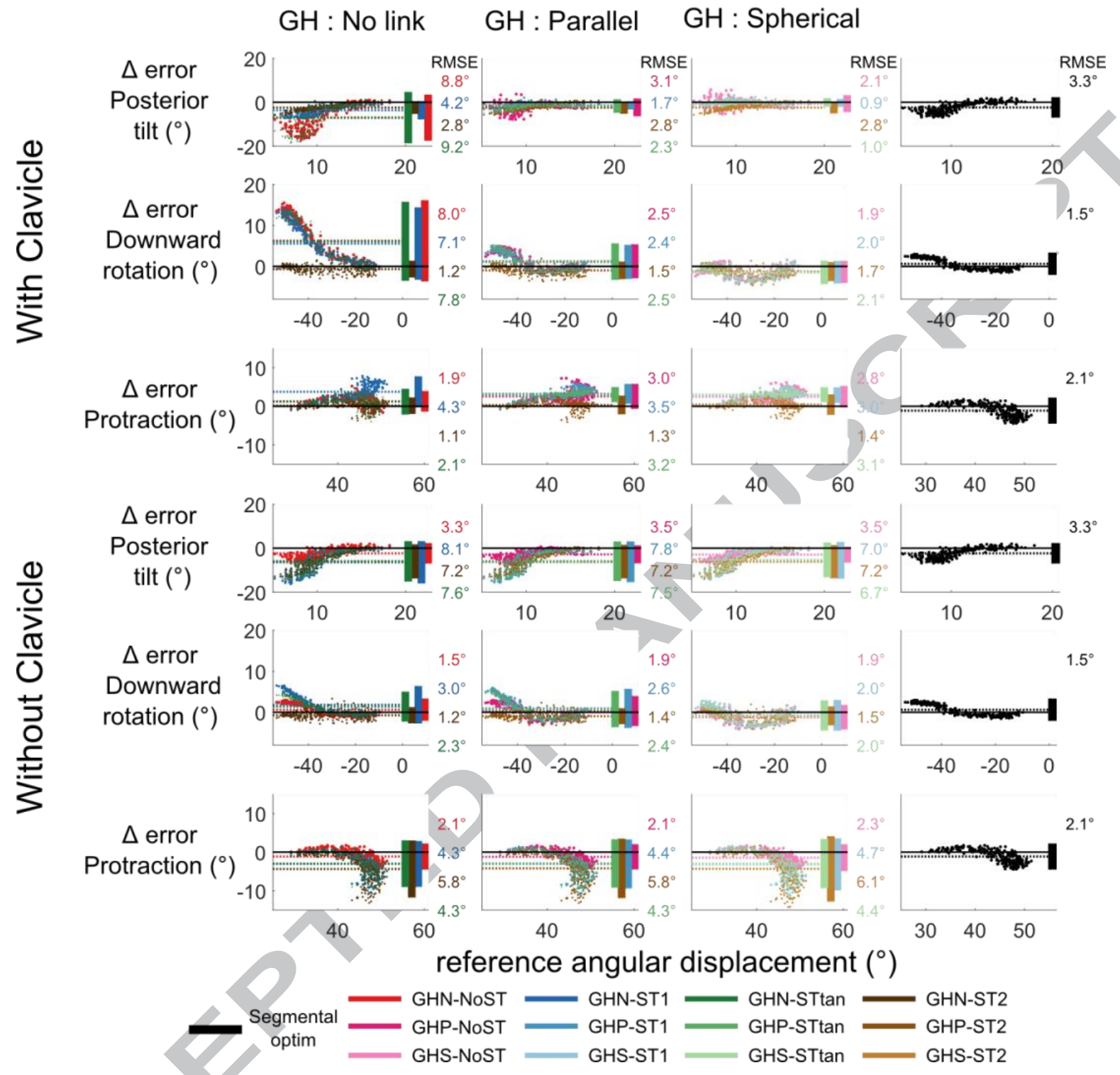

Figure S1: Bland-Altman plots during the flexion movement for the 24 different multibody kinematics optimisation models and the segmental optimisation.

Note: GHN: No Glenohumeral joint, GHP: Glenohumeral parallel mechanism; GHS Glenohumeral spherical joint; ST1: one scapulothoracic point; ST2: two scapulothoracic points; STTan: tangential scapulothoracic contact; NoST: no scapulothoracic joint. 


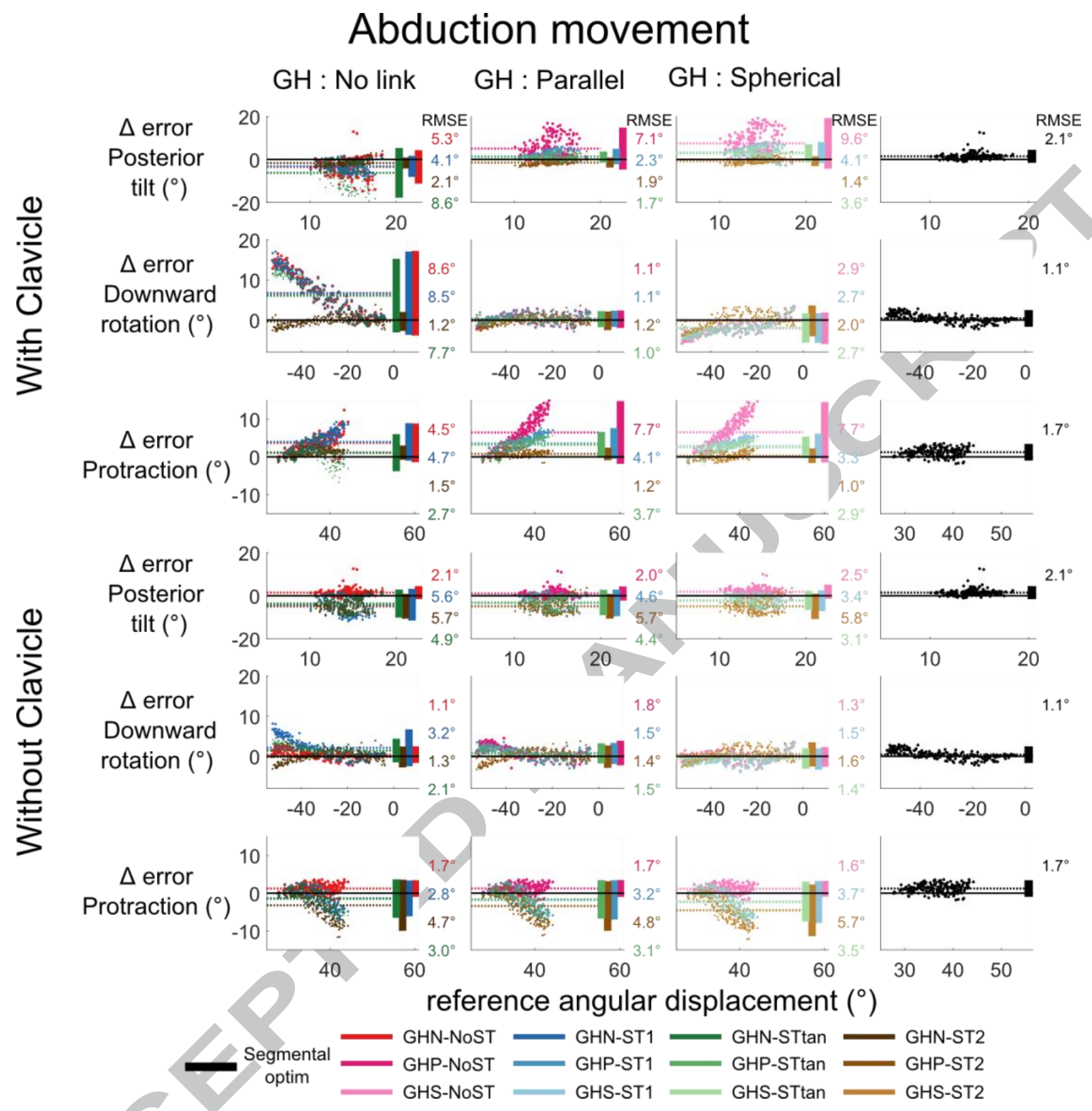

Figure S2: Bland-Altman plots during the abduction movement for the 24 different multibody kinematics optimisation models and the segmental optimisation.

Note: GHN: No Glenohumeral joint, GHP: Glenohumeral parallel mechanism ; GHS Glenohumeral spherical joint; ST1: one scapulothoracic point; ST2: two scapulothoracic points; STTan: tangential scapulothoracic contact; NoST: no scapulothoracic joint. 